\title{
Canadian Urological Association guideline on perioperative thromboprophylaxis and management of anticoagulation
}

\author{
Philippe D. Violette ${ }^{1,2,3}$; Luke T. Lavallée ${ }^{4}$; Wassim Kassouf ${ }^{5}$; Peter L. Gross ${ }^{6}$; Bobby Shayagan ${ }^{3}$ \\ ${ }^{1}$ Department of Health Research Methods Evidence and Impact (HEI), McMaster University, Hamilton, ON, \\ Canada; ${ }^{2}$ Department of Surgery, Western University, London, ON, Canada; ${ }^{3}$ Department of Surgery, Division of \\ Urology, McMaster University, Hamilton, ON, Canada; ${ }^{4}$ The Ottawa Hospital and Ottawa Hospital Research \\ Institute, Division of Urology, Department of Surgery, The University of Ottawa, Ottawa, ON, Canada; ${ }^{5}$ Department \\ of Surgery, Division of Urology, McGill University Health Centre, Montreal, QC, Canada; ${ }^{6}$ Department of \\ Medicine, Division of Hematology and Thromboembolism, McMaster University, Hamilton, ON, Canada
}

Cite as: Can Urol Assoc J 2018 December 14; Epub ahead of print. http://dx.doi.org/10.5489/cuaj.5828

Published online December 14, 2018

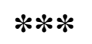

\section{Introduction}

Surgery exposes patients to a risk of venous thromboembolism (VTE) and bleeding. Venous thromboembolism includes deep vein thrombosis (DVT) and pulmonary embolism (PE), which represent serious and sometimes fatal consequences of surgery. Therefore, optimizing treatment plans to reduce VTE risk while also minimizing bleeding risk is important to patients and the health care system. The goal of this CUA guideline is to provide a structured approach to the prevention of perioperative thromboembolic events that may be applied in Canada.

In this guideline, two forms of perioperative VTE prophylaxis are considered. The first is prophylaxis used for primary prevention VTE for patients undergoing surgery. The second, is management of an anticoagulant or antiplatelet agent used for treatment or as a form of secondary prevention during the perioperative period. The CUA thromboprophylaxis guideline panel feel that it is important for urologists to be engaged in the discussion and management in each of these situations. The panel recognizes that in many clinical contexts other specialists including, internists, cardiologists, neurologists and hematologists, may also be involved in this aspect of patient care. The guidance provided in this document is intended to help urologists engage with their patients and colleagues in a collaborative context. The guidance provided in this document is intended to reflect best practice for the usual case for a specific surgery and patient population. This guideline is not intended for unusual conditions or circumstances, which are typically rare, and should be addressed involving appropriate specialists on a case by case basis. 
Decisions regarding thromboprophylaxis involve a trade-off, in which the intended purpose is to decrease the risk of VTE, while recognizing that thromboprophylaxis also increase the risk of bleeding. A systematic review and meta-analysis of randomized placebo-controlled trials, performed for the American College of Chest Physicians VTE guideline, reported that VTE prophylaxis decreases the relative risk of VTE by $50 \%$ and increases the relative risk of bleeding by $50 \%{ }^{1}$. In cases where the risk of VTE is high and the bleeding risk is low, VTE prophylaxis is usually warranted because the net benefit is favorable. When the risk of VTE is low and of the bleeding risk is high, VTE prophylaxis may be harmful and is usually not warranted. In many cases, the tradeoff between VTE prevention and bleeding risk may be close, and the "most favorable" approach to VTE prophylaxis is less clear. In these situations, individual patient values and preferences must be considered to determine the "best management plan” (Fig. 1).

Proper evaluation of the risks and benefits of thromboprophylaxis for urological surgery requires both procedure and patient specific knowledge ${ }^{2-4}$. To judge the net benefit of VTE prophylaxis one must know the surgery-specific baseline risk of VTE and major bleeding. For a given procedure the baseline risk of VTE may be further increased by patient factors. To be clinically applicable, use of individual patient data for risk stratification must be easy to apply and sufficiently discriminative ${ }^{5}$. Lastly, a threshold (cutoff) of magnitude of benefit is needed to allow for consistent recommendations across different types of surgeries in different patient populations. It is with these considerations in mind that the CUA guideline panel on thromboprophylaxis chose to frame their recommendations.

\section{Methodology}

\section{Creating a de novo guidelines vs. endorsing and/or adapting existing guidelines}

The CUA guideline panel first determined if a CUA guideline is needed for VTE prophylaxis. To address this issue, three questions were posed. First, are perioperative VTEs a clinically relevant problem and is there uncertainty about the best prophylactic management? Second, is there variation in practice within the subject area? Third, is currently available guidance sufficiently inadequate to require creation of a new guideline.

Applying these 3 questions, the panel concluded that adapting or endorsing an existing guideline would be most appropriate.

In brief, the panel believes that perioperative VTE prophylaxis is a clinically relevant problem because VTEs are associated with morbidity and mortality among patients who undergo urological surgery ${ }^{6-8}$. There appears to be considerable variation in VTE prophylaxis strategies in Canada and internationally ${ }^{9-11}$. Additionally, the CUA membership indicated a strong interest for a CUA VTE guideline in a member survey conducted by CUA office of education in 2016. This survey identified VTE prophylaxis as an area of unaddressed need and as a result a continuing professional development teaching program was created. This program is available to CUA 
members on the member portal. Regarding existing clinical guidance, the panel is aware of a number of medical, oncological and surgical VTE guidelines, which are not urology specific and generally do not weight the tradeoff between VTE prevention and bleeding explicitly ${ }^{12}$. Most recently, the European Association of Urology (EAU) published a VTE guideline that is current and urology procedure specific. Additionally, the EAU guideline was developed using rigorous methodology (GRADE approach), and source materials are all publicly available ${ }^{4,13,14}$. Importantly, the EAU guideline addressed the intended scope of the CUA. In considering these factors the panel felt that it would be most appropriate to adapt or endorse the recently published EAU guideline ${ }^{15}$.

\section{Adopting or adapting the EAU VTE guideline for the CUA: The modified ADAPTE framework}

Several methodological approaches exist to adapt or endorse an existing guideline ${ }^{16}$. There have not been systematic assessments of rigor, efficiency or transparency of these methods. Two methodologic frameworks appealed to the Panel given the context and desire to use the GRADE framework ${ }^{17-19}$. The first is the GRADE-ADOLOPMENT process which is comprised of 8 steps and has been developed specifically to adapt GRADE guidelines to local contexts ${ }^{20}$. The second, is a modification of the original 22 step ADAPTE process simplified to five-steps that was specifically designed to modify the American College of Chest Physicians Thromboprophylaxis Guidelines (ACCP-AT9) to a specific country's context ${ }^{21-22}$. The Panel elected to follow the latter approach given its simplicity and similarities between its development and the CUA panel's objectives.

Summary of the process used to adapt EAU guideline for the Canadian context To adapt the EAU VTE guidelines to the Canadian context we followed a five-step process as follows: 1planning, 2-initial assessment of the recommendations, 3-modification, 4-publication, and 5evaluation $^{21-22}$.

The planning steps occurred after publication of the EAU guideline and underpinning meta-analyses in March 2017 ${ }^{13-15}$. At this time a CUA VTE panel was convened, met in person, decided on scope, and discussed methodological elements of the guideline to be adopted.

Furthermore, the Panel confirmed the methodological approach to be used for adapting the EAU guideline to the Canadian context. Each panel member independently reviewed each EAU guideline, all EAU recommendation, methodology, source documents and appendices. Each member independently assigned one of 3 possible actions for each of the 32 recommendations (adopt, exclude, modify). Recommendations deemed entirely applicable to the Canadian context and without methodological concern were adopted without modification. Recommendations deemed not applicable or beyond the scope of the CUA Panels objectives were excluded. The remaining recommendations were considered for modification based on: a) the balance between benefits and harms, b) confidence in the estimates of the effect of the interventions under 
consideration, c) extent of assumed variability in patient values and preferences d) resource and health equity considerations. Additionally, new topics or concerns not covered in the EAU guideline documents were also identified for further discussion by the Panel. Decisions regarding adoption, exclusion, modification, and new topics were agreed upon by Panel consensus.

In summary, the Panel reviewed the 32 EAU recommendations and their supporting source data. All panelists independently selected 14 of the 32 EAU recommendations for adoption without modification. These recommendations were not discussed further individually, however they were considered when choosing how to frame recommendations and simplify the overall presentation of clinical guidance. As a result, several recommendations from the EAU guideline were combined to reduce the overall number of recommendations in the CUA document, reducing these from 14 to 11 . The remaining 18 of 32 recommendations were discussed by the Panel for modification or exclusion. As a result of this process, 14 recommendations were modified into 7 and four were excluded. The Panel excluded 4 recommendations because they were beyond the scope of the CUA objectives and were replaced with one clinical principle. The rationale and judgments made to justify modification of the remaining recommendations are detailed in the text of this guideline. Therefore, this CUA Guideline includes 18 recommendations and 1 clinical principle.

Five additional topics were identified as inadequately addressed or unclear for Canadian readership within the EAU guideline. These were 1) availability and cost of prophylactic agents in different Canadian jurisdictions, 2) explanation and justification for timing of initiation of thromboprophylaxis, 3) the role of direct acting oral anticoagulants (DOACs) for post-operative thromboprophylaxis in urological surgery, 4) role of perioperative tranexamic acid (TXA) to reduce bleeding, 5) the possible association between neoadjuvant chemotherapy and VTE for patients who undergo surgery (ex: radical cystectomy). The Panel considered each topic for inclusion in the CUA Guideline. The role of DOACs, tranexamic acid and the impact of neoadjuvant chemotherapy on VTEs were felt to be important issues that should be addressed either as a separate guidance document or subsequent iteration of this guideline.

\section{How to interpret Strong and Weak recommendations}

The CUA Guideline Steering Committee and CUA Executive have committed to conducting and reporting CUA guidelines using the GRADE framework when possible. A detailed explanation of GRADE is outside the scope of this document, but an overview is available as short series in the British Medical Journal ${ }^{17-19}$ and a more detailed elaboration in a series of methodology articles $^{23}$ (CUA GRADE reference sheet available as supplementary material at cuaj.ca). A webcast of the introductory CUA-GRADE workshop is also available for viewing by CUA membership (http://tech4pco.com/cua/videos/cua-grade-workshop?keycode=login).

Four types of recommendations are possible in the GRADE framework; strong for, weak for, weak against and strong against. These represent a spectrum of guidance that depend on both the relative tradeoff of good and bad outcomes and the quality of the evidence 


\section{Guideline: Perioperative thromboprophylaxis \& anticoagulation management}

(i.e certainty in the estimates of effect for each outcome). By convention, when a strong guidance statement is made the panel Recommends a course of action. Conversely, when a weak statement is made the Panel Suggests a course of action.

In the context of thromboprophylaxis, the main benefit of the intervention is prevention of symptomatic VTE, and the main harm is an increased risk of major bleeding. When the balance of evidence clearly supports a benefit or harm to the tradeoff $\underline{\text { AND }}$ there is high certainty in the estimates of effect (good quality evidence, low risk of bias) a strong recommendation for, or against VTE prophylaxis is made. In scenarios where there appears to be benefit or harm from an intervention, but there is less certainty in the estimates of effect, a weak recommendation for or against is made. In some scenarios, there may be high certainty in our evidence but the tradeoff is close. In these situations we also make a weak recommendation for or against.

\section{How to interpret and apply the CUA GRADE guidelines for VTE prophylaxis to patients?}

A strong recommendation is one in which the large majority of patients (typically $>90 \%$ ) in this situation would agree with the recommended course of action. This is a situation of informed consent in which the patient accepts or declines the recommended course of action. A weak recommendation indicates there is less certainty regarding the best course of action and management is more strongly dependent on individual patient values and preferences (i.e.: desire to avoid VTE complications and burden of treatment vs. desire to avoid bleeding complications). This is a situation of shared decision making and weighing the importance of outcomes from the individual patient's point of view.

To make clear recommendations, a cutoff for the magnitude of net benefit is required. The EAU Guideline proposed a cutoff for recommendation based on indirect evidence from patient values and preference studies in a population who were prescribed a LMWH for a nonsurgical reason ${ }^{24,25}$. Ideally, studies evaluating the values and preferences of patients receiving LMWH as post-operative prophylaxis should be used. The CUA Panel was not able to identify such a study. The Panel discussed at length whether to adopt the cutoffs proposed in the EAU Thromboprophylaxis guideline vs. generating a new evidence-based cutoff. The CUA Panel, judged that it was not feasible to complete new studies in a timely fashion, thus the Panel elected

to adhere to the cutoffs as described in the EAU thromboprophylaxis guideline ${ }^{15}$. This is an area in need of future research.

\section{Timing and duration of pharmacological thromboprophylaxis with surgery}

The goal of perioperative thromboprophylaxis is to reduce symptomatic VTEs while minimizing any increased risk of major bleeding. Major bleeding is defined as bleeding requiring reoperation, embolization, or causing death. It is therefore important to consider when VTEs and major bleeding usually manifest when considering the recommended timing and duration of thromboprophylaxis. The incidence of VTE is highest and roughly linear in the first 4 weeks after surgery and reduces substantially thereafter (Figs. 2, 3). The incidence of major bleeding is 
highest on the day of surgery and decreases rapidly over the next 5 days (Figure 3). Therefore one strategy to improve the net benefit of guideline recommendations is to recommend starting prophylaxis after the period of highest bleeding risk and continue prophylaxis for the duration of highest VTE risk. This strategy may slightly increase the short term incidence VTE, but should also decrease major bleeding episodes by a greater amount since most bleeding will occur on the day of surgery.

\section{Recommendations for use of VTE prophylaxis in urological surgery}

Preamble: The following recommendations apply to the use of low molecular weight heparin (LMWH) as prophylactic agent, starting the morning after surgery and continuing for 28 days as compared to not giving any pharmacological prophylaxis.

VTE and bleeding risks depend on patient factors and surgical factors. Recommendations presented below are for specific surgery types accounting for the tradeoff of symptomatic VTE (DVT, PE or Death from VTE) and major bleeding (requiring re-operation, embolization, or death) for specific surgeries. The impact of surgery on VTE risk is affected by patient level factors. Recommendations below refer to a patient risk stratification for VTE as proposed by

Tikkinen et al. and adopted by the European Association of Urology ${ }^{4}$. This risk stratification summarizes the most compelling, patient level risk factors based on data from other models of VTE risk including Caprini, Rogers, Panucci and large population based studies ${ }^{4}$. Four factors were identified with associated relative increase in VTE risk as shown in table 1.

\section{VTE prophylaxis recommendations for oncological urological surgery}

Radical cystectomy performed by open or robotic approach

Recommendation 1: For patients undergoing radical cystectomy by either open or robotic approach regardless of VTE risk stratification, we recommend the use of pharmacological prophylaxis (Strong recommendation, strong quality of evidence) and suggest use of mechanical prophylaxis (Weak recommendation, low quality evidence).

Judgment: In Canada radical cystectomy is predominantly an open procedure for which higher quality evidence was available, therefore the Panel felt confident in making a strong recommendation. Regarding robotic approach the estimated effects for bleeding and VTE were very similar and parallel those for the open procedure, from which we infer that net benefit will likely remain similar between two approaches despite lower certainty in estimates (low quality evidence) for the robotic approach.

\section{Radical prostatectomy}

Note: Radical prostatectomy is a procedure whose dissection may vary by the perceived severity of prostate cancer treated. As such the panel recognizes that significant differences in procedure may occur when treating less aggressive or more aggressive disease. The extent of lymph node dissection performed may increase with the severity of disease and this factor also increases VTE 
risk. Therefore recommendations for prophylaxis are additionally stratified by extent of lymph node dissection as well as patient and procedure type. Extent of lymph node dissection is stratified as follows: No lymph node dissection, Standard dissection (Node of Cloquet, along external iliac vein up to the bifurcation of the internal and external iliac, obturator fossa), Extended dissection (Standard dissection and dissection above bifurcation of iliac vessels or including presacral, precaval or preaortic nodes).

Open radical prostatectomy without an extended lymphadenectomy

Recommendation 2: For patients undergoing open radical prostatectomy without lymph node dissection or standard lymph node dissection

- $\quad$ at low risk of VTE, we suggest use of pharmacologic prophylaxis (Weak recommendation, moderate-high quality of evidence)

- $\quad$ at moderate or high risk of VTE we recommend use of pharmacological prophylaxis (Strong recommendation, moderate-high quality of evidence)

- mechanical prophylaxis is suggested for all patients (Weak recommendation, lowquality evidence).

Open radical prostatectomy with extended lymph node dissection

Recommendation 3: For all patients undergoing open radical prostatectomy with extended lymph node dissection we recommend pharmacological prophylaxis (Strong recommendation, Moderate-high quality evidence) and suggest mechanical prophylaxis (Weak recommendation, low-quality evidence).

Judgment: For patients with low VTE risk who undergo open prostatectomy with no lymph node dissection or standard dissection the net benefit only weakly favors giving thromboprophylaxis due to close tradeoff of harms and benefit. We considered combining Recommendation 2 and 3 but recognize that there may be a substantial proportion of patients with few risk factors who undergo prostatectomy with a standard lymph node dissection and decision may be value sensitive for some patients in this context.

Robotic or laparoscopic radical prostatectomy

Recommendation 4: For patients undergoing robotic or laparoscopic radical prostatectomy with no lymph node dissection

- at low risk for VTE we recommend against use of pharmacological prophylaxis (Strong recommendation, Moderate-quality evidence), without mechanical prophylaxis (Weak recommendation, Moderate-quality evidence).

- $\quad$ at moderate or high risk of VTE we suggest against use of pharmacologic prophylaxis (Weak recommendation, Moderate-quality evidence) with mechanical prophylaxis (Weak recommendation, Moderate-quality evidence). 


\section{Guideline: Perioperative thromboprophylaxis \& anticoagulation management}

Recommendation 5: For patients undergoing robotic or laparoscopic radical prostatectomy with standard lymph node dissection

- $\quad$ at low VTE risk, we recommend against the use of pharmacologic prophylaxis (strong recommendation, Moderate quality evidence)

- $\quad$ at moderate risk of VTE we suggest against (weak recommendation, moderate quality evidence)

- $\quad$ at high risk of VTE we suggest for the use of pharmacological prophylaxis (weak recommendation, moderate quality evidence)

- mechanical prophylaxis is suggested for all patients (Weak recommendation, weak evidence).

Recommendation 6: For patients undergoing robotic or laparoscopic radical prostatectomy with extended lymph node dissection

- $\quad$ at low risk of VTE we suggest against using pharmacological prophylaxis (weak recommendation, moderate quality evidence)

- $\quad$ at moderate risk of VTE we suggest for use of pharmacological prophylaxis (Weak for, moderate-high quality evidence)

- $\quad$ at high risk VTE we recommend for use of pharmacologic prophylaxis (Strong for, moderate to high quality evidence)

- mechanical prophylaxis is suggested for all patients (weak for, low-quality of evidence).

Judgement: recommendations for laparoscopic and robotic approach were combined to simplify guideline reporting and reduce the number of recommendations. We recognize that estimate of effect for bleeding and VTE may vary considerably for these two procedures ${ }^{13}$ and we did not attempt to combine these. We recognized that the net benefit for either laparoscopic or robotic prostatectomy led to the same recommendations in all but one situation of a high risk patient undergoing a standard PLND. In this instance the difference in net benefit was 10/1000 as compared to 6.3/1000 for laparoscopic and robotic approaches respectively, which did not change the direction of recommendation but only the strength. As a panel, given the borderline value of 10/1000 we chose to place a higher value on encouraging explicit discussion of patient values and preferences and made a weak recommendation for in this situation.

Open renal surgery for cancer

Recommendation 7: For patients undergoing open radical or partial nephrectomy or nephroureterectomy we suggest use of pharmacological thromboprophylaxis (Weak for, very low to Low-quality evidence) and mechanical prophylaxis (Weak for, low-quality evidence). 
Recommendation 8: For patients undergoing laparoscopic radical nephrectomy

- $\quad$ at low or moderate risk of VTE we suggest against the use of pharmacologic prophylaxis (weak against, very low-quality evidence),

- at high VTE risk we suggest for use of pharmacologic prophylaxis (weak for, very low-quality evidence)

- mechanical prophylaxis is suggested for all patients (weak for, low-quality evidence).

Recommendation 9: For patients undergoing laparoscopic partial nephrectomy

- $\quad$ at low or moderate risk of VTE we suggest against the use of pharmacological VTE prophylaxis (weak against, low-quality evidence),

- $\quad$ at high risk of VTE we recommend for use of pharmacological VTE prophylaxis (Strong for, moderate quality evidence),

- Mechanical prophylaxis is suggested for all patients (weak for, low-quality evidence).

For patients undergoing laparoscopic nephroureterectomy

Judgment: Laparoscopic nephroureterectomy was not evaluated in the EAU VTE guideline due to lack of data. We performed an updated literature search but failed to identify compelling series that reported VTE and bleeding outcomes as well as proportion of prophylaxis use. In the Canadian context we believe that a large number of nephroureterectomy are performed laparoscopically with open bladder cuff or entirely laparoscopically. We felt that it was not feasible at this time to generate a de novo recommendation for this procedure. In the absence of data, we suggest to follow recommendation 8 for patients undergoing laparoscopic nephroureterectomy.

Robotic renal surgery for cancer

Recommendation 10: For patients who are undergoing robotic partial nephrectomy

- at low-risk of VTE we suggest against use of pharmacological prophylaxis (weak against, moderate quality evidence)

- at moderate risk of VTE we suggest use of pharmacological prophylaxis (weak for, moderate quality-evidence)

- $\quad$ at high risk we recommend use of pharmacological prophylaxis (strong for, moderate quality evidence)

- mechanical prophylaxis is suggested for all patients (weak for, low-quality evidence)

Judgment: The Panel recognizes that some Canadian urologists may perform radical nephrectomy or nephroureterectomy by robotic approach but we believe that this is a minority. Use of thromboprophylaxis for these procedures is not well reported in the literature. In the absence of data we suggest following recommendation 8 for these procedures.We recommend that if there is increased use of robotic radical nephrectomy or nephroureterectomy in Canada that this decision be revisited in future iterations of this guideline. 


\section{Retroperitoneal lymph node dissection (RPLND)}

Recommendation 11: For all patients undergoing retroperitoneal lymph node dissection (RPLND) for testicular germ cell tumor, we suggest use of pharmacological prophylaxis (Weak for, very low-quality evidence) and suggest use of mechanical prophylaxis (weak for, lowquality evidence).

Judgment: The panel recognizes that post chemo RPLND likely has higher VTE risk and possibly higher bleeding risk than primary RPLND. However, this procedure is infrequently performed and as such there is a paucity of reliable data from which to derive estimates of effect for these outcomes. The independent effect of exposure to cisplatin chemotherapy may be calculable, but for pragmatic reasons was felt not to be within the scope of the current iteration of this guideline. We suggest these situations be considered on a case by case basis. Until better data emerges it may be reasonable to apply guidance for primary RPLND to the post-chemo setting.

\section{VTE prophylaxis recommendations for non-oncological urological surgery}

Recommendation 12: For all patients undergoing ambulatory day surgery, who are not admitted to hospital, regardless of individual patient VTE risk we recommend against use of pharmacological prophylaxis (Strong against, moderate quality evidence) and recommend against use of mechanical prophylaxis (weak against, low-quality evidence)

Judgment: The Panel believes that incidence of VTE in this population is sufficiently low that it is unlikely attributable to surgical intervention rather than baseline risk of VTE, however risk of bleeding will be elevated, typically by a very small magnitude, regardless of surgery. Therefore in all cases extended prophylaxis is not warranted.

Recommendation 13: For all patients who undergo transurethral resection of the prostate (TURP), we suggest against use of pharmacological prophylaxis (weak against, very low quality evidence), and we suggest against use of mechanical prophylaxis (Weak against, very low quality evidence).

Judgment: We placed a higher value on making fewer recommendations in an attempt to facilitate clinical uptake of this guideline then the very borderline improvement in net benefit (2.9 per 1000 where a priori cutoff was 2.5 per 1000) among patients at high risk for VTE undergoing TURP. Therefore we suggest against use of mechanical prophylaxis in all patients undergoing TURP rather than making separate recommendations for high risk patients.

Recommendation 14: For patients undergoing donor nephrectomy for transplantation or nephrectomy for benign disease or recipient transplant

- at low or moderate risk of VTE we suggest against use of pharmacological prophylaxis (weak against, very low to low quality evidence) without mechanical prophylaxis 
- $\quad$ at high risk of VTE we suggest the use of pharmacological prophylaxis (weak for, very low to low-quality evidence) and mechanical prophylaxis (weak for, low quality evidence)

Judgment: This does not preclude the use of anticoagulation for other reasons such as graft thrombosis which are outside of the scope of this recommendation.

Recommendation 15: For all patients undergoing surgery for continence or prolapse, we suggest against the use of pharmacological prophylaxis (weak against, very low to low quality evidence) and suggest against use of mechanical prophylaxis (weak against, low quality evidence)

\section{Recommendations for bridging of anticoagulation and antiplatelet agents}

Note: Guidance below is intended to inform Canadian urologists about best practice for common situations. The panel recognizes that in many cases, peri-operative management of anticoagulation may require a multidisciplinary approach, which may include hematology, internal medicine or cardiology. The Panel recommends the treating urologist consider each patient scenario individually to determine appropriate management and consider consultation with a physician with expertise in thrombosis for any patient encounters that is not standard.

\section{Definition}

Patients are considered to be at very high risk of thrombosis if any one of the following are present:

- drug-eluting stent placement within six months

- $\quad$ bare metal stent placement within six weeks

- $\quad$ transient ischemic attack (TIA) stroke within 30 days

- new incidence of VTE within 1 month

- severe thrombophilia (such as antithrombin deficiency, antiphospholipid antibody or other as identified by appropriate specialist)

- cage-ball mechanical heart valves

Recommendation 16: in patients receiving an antiplatelet agent who do not have a very high risk of thrombosis (see definition) the panel recommends stopping antiplatelet agents 7 days prior to surgery without bridging (strong for, high quality evidence) and restarting antiplatelet therapy $\underline{4}$ days post-surgery as compared to a longer period off therapy (strong for, moderate quality evidence).

Recommendation 17: in patients receiving an anticoagulant agent who do not have very high risk of thrombosis (see definition) the panel recommends stopping prior to surgery without bridging therapy (strong for, high quality evidence) and restarting 4 days post-surgery as compared to a longer period off therapy (strong for, moderate quality evidence). The recommended duration off anticoagulation prior to surgery varies by therapy as follows:

- Direct oral anticoagulants (Dabigatran, apixaban, edoxaban, rivaroxaban) 3 days prior

- Warfarin 5 days prior 


\section{Guideline: Perioperative thromboprophylaxis \& anticoagulation management}

- $\quad$ LMWH (therapeutic dosing) 12 hours (if BID dosing) or 24 hours (if once daily dosing) prior

- Fondaparinux 24 hours prior Note:

Renal function may DOAC clearance and prolong anticoagulant activity. For patients with impaired renal function DOAC may need to be stopped longer than 3 days prior to surgery. The panel elected to modify the timing of stopping anticoagulant or antiplatelet agents to be consistent with guidance from Thrombosis Canada ${ }^{26}$. Additionally, the PAUSE study (https://clinicaltrials.gov/ct2/show/NCT02228798) once reported may provide important information on the optimal timing of stopping DOAC and should be addressed in subsequent iterations of this guideline.

Recommendation 18: For patients at very high risk of thrombosis in whom surgery can be delayed until the period of very high risk is completed should have surgery delayed until the period of very high risk is over (Strong for, high quality evidence).

Clinical principle- For patients at very high risk of thrombosis in whom surgery cannot be delayed our panel recommends multidisciplinary discussion and individualized treatment plan.

Judgment: The panel is of the opinion that situation in which patients are at very high risk of thrombosis and surgery cannot be delayed will be rare and benefit from involvement of multiple specialties and patient values and preferences to weigh risks and benefits of a tailored management approach. We felt that it was not within the scope of Canadian urological practice to proceed in these situations without further consultations with specialists from appropriate disciplines.

\section{Limitations, further research, and subsequent iterations of this guideline}

In completing the modified ADAPTE process for this guideline the Panel has identified several areas in need of further research to improve subsequent iterations and contribute to the field of perioperative thromboprophylaxis in general. Many recommendations are weak for two reasons, due to limitations in the quality of the body of evidence available for outcomes related to some procedures, and/or due a close tradeoff of benefits and harms for other situations. These limitations highlight a clinical research domain in need of more attention to improve the quantity and quality of data available to direct best care. Specifically, there is a need for more published surgical series that include data on thromboprophylaxis use and outcomes (including VTE and bleeding), especially for procedures not covered in this guideline.

Additionally, weighing the net benefit of close tradeoffs is highly dependent on patient values and preferences. Different stakeholders may view different magnitudes of net benefit as sufficient to recommend use of prophylaxis. The current recommendations have a clinical emphasis and attempt to account for patient values and preferences in determining sufficient magnitude of net benefit for a strong recommendation (10 per 1000). However due to the paucity of evidence available on patient values and preferences in this area, indirect evidence from 
different a patient population was used rather than post-op surgical patient. Improved estimates of patient values and preferences may impact the strength and direction recommendations in future iteration of this guideline.

The optimal timing and duration of prophylaxis is also controversial and based on very little direct evidence. Recommendations in this CUA guideline are based on modelling studies of large data sets that are consistent with the published literature. However, direct comparisons of the effect of pharmacological prophylaxis before and after surgery are not available. We base our judgment on the relative merit of reducing bleeding on the day of surgery to the increase in VTE risk during this period. While the panel felt this was reasonable consideration of the tradeoffs of bleeding and VTE, direct evidence from randomized studies would strengthen our certainty in this assumption. Additionally, the approach to patient level risk stratification adopted by the Panel, is a consequence of the approach used to value the tradeoff between bleeding and VTE based on procedure specific baseline risks. A procedure specific baseline risk account for procedure specific variables such as "pelvic surgery” or "presence of malignancy”. Therefore a risk stratification of pertinent patient factors was used rather than a risk stratification approach that uses both patient and procedure factors such as Caprini ${ }^{2,5}$. Consequently, this risk stratification approach has not been tested empirically. Future iterations of this guideline will benefit from validation studies of the EAU patient risk stratification approach.

Lastly, thrombosis research is a rapidly changing field with newer agents emerging as reasonable alternatives, most of which have yet to be evaluated in the urological context. It is our hope that subsequent CUA guidance on thromboprophylaxis will also consider the role of direct oral anticoagulants (DOAC) and tranexamic acid in striking the right balance to minimize bleeding and reduce thrombosis. 


\section{References}

1. Gould MK, Garcia DA, Wren SM, Karanicolas PJ, Arcelus JI, Heit JA, Samama CM, American College of Chest Physicians: Prevention of VTE in nonorthopedic surgical patients: antithrombotic therapy and prevention of thrombosis, 9th ed: American College of Chest Physicians Evidence- Based Clinical Practice Guidelines. Chest 2012, 141(Suppl 2):e227S-e277S.

2. Caprini JA, Arcelus JI, Reyna JJ. Effective risk stratification of surgical and non-surgical patients for venous thromboembolic disease. Semin Hematol. 2001;38(suppl 5):12-19

3. Bahl V, Hu HM, Henke PK, Wakefield TW, Campbell DA Jr, Caprini JA. A validation study of a retrospective venous thromboembolism risk scoring method. Ann Surg. 2010 Feb;251(2):344-50.

4. Tikkinen KA, Agarwal A, Craigie S et al. Systematic reviews of observational studies of risk of thrombosis and bleeding in urological surgery (ROTBUS): introduction and methodology. Syst Rev 2014; 23: 150. doi:10.1186/2046-4053-3-150.

5. McAlpine K, Breau RH, Mallick R, Cnossen S, Cagiannos I, Morash C, Carrier M, Lavallée LT. Current guidelines do not sufficiently discriminate venous thromboembolism risk in urology. Urol Oncol. 2017 Jul;35(7):457.e1-457.e8. doi: 10.1016/j.urolonc.2017.01.015. Epub 2017 Feb 15. PMID:28214280

6. Quek ML, Stein JP, Daneshmand S, et al. A critical analysis of perioperative mortality from radical cystectomy. J Urol 2006;175(3 Pt 1):886-90.

7. Trinh VQ, Karakiewicz PI, Sammon J, et al. Venous thromboembolism after major cancer surgery: temporal trends and patterns of care. JAMA Surg 2014;149:43-9.

8. Tyson MD, Castle EP, Humphreys MR, Andrews PE: Venous thromboembolism after urological surgery. J Urol 2014, 192:793-797.

9. Sterious S, Simhan J, Uzzo RG et al. Familiarity and self-reported compliance with American urological association best practice recommendations for use of thromboembolic prophylaxis among American Urological Association members. J Urol 2013; 190: 992-8.

10. Pridgeon S, Allchorne P, Turner B, Peters J, Green J. Venous thromboembolism (VTE) prophylaxis and urological pelvic cancer surgery: a UK national audit. BJU Int 2015; 115: 223-9.

11. Violette PD, Vernooj RWM, Aoki Y, Agarwal A, Cartwright R, Arai Y, Tailly T, Novara G, Craigie S, Breau RH, Guyatt G, Tikkinen K. An international survey on the use of thromboprophylaxis in urological surgery (ISTHMUS): large practice variation within and between countries CUAJ 2017; 11(6Suppl4): S217.

12. Violette PD, Cartwright R, Briel M, Tikkinen KA, Guyatt GH. Guideline of guidelines: thromboprophylaxis for urological surgery. BJU Int. 2016 Sep;118(3):351-8.

13. Tikkinen KA, Craigie S, Agarwal A, Violette PD, Novara G, Cartwright R, Naspro R, Siemieniuk RA, Ali B, Eryuzlu L, Geraci J, Winkup J, Yoo D, Gould MK, Sandset PM, Guyatt GH. Procedure-specific risks of thrombosis and bleeding in urological cancer 
surgery: systematic reviews and meta-analyses. Eur Urol 2017 Mar 23. pii: S03022838(17)30173-2

14. Tikkinen KA, Craigie S, Agarwal A, Siemieniuk RA, Cartwright C, Violette PD, Novara G, Naspro R, Agbassi C, Ali B, Imam M, Ismaila N, Kam D, Gould MK, Sandset PM, Guyatt GH. Procedure-specific risks of thrombosis and bleeding in urological non-cancer surgery: systematic reviews and meta-analyses. Eur Urol 2017 Mar 9. pii: S03022838(17)30114-8.

15. Tikkinen KAO, Cartwright R, Gould MK, Naspro R, Novara G, Sandset PM, Violette PD, Guyatt GH. Thromboprophylaxis in urological surgery. European Association of Urology Guidelines Office 2017. Accessed from https://uroweb.org/guideline/thromboprophylaxis/ March 2017.

16. Darzi A, Abou-Jaoude EA, Agarwal A, Lakis C, Wiercioch W, Santesso N, Brax H, ElJardali F, Schünemann HJ, Akl EA A methodological survey identified eight proposed frameworks for the adaptation of health related guidelines. J Clin Epidemiol. 2017 Jun;86:3-10.

17. GH, Oxman AD, Vist GE, Kunz R, Falck-Ytter Y, Alonso-Coello P, Schünemann HJ; GRADE Working Group. GRADE: an emerging consensus on rating quality of evidence and strength of recommendations. BMJ. 2008 Apr 26;336(7650):924-6

18. Guyatt GH, Oxman AD, Kunz R, Vist GE, Falck-Ytter Y, Schünemann HJ; GRADE Working Group. What is "quality of evidence" and why is it important to clinicians? BMJ. 2008 May 3;336(7651):995-8.

19. Guyatt GH, Oxman AD, Kunz R, Falck-Ytter Y, Vist GE, Liberati A, Schünemann HJ; GRADE Working Group. Going from evidence to recommendations. BMJ. 2008 May 10;336(7652):1049-51.

20. Schünemann HJ, Wiercioch W, Brozek J, Etxeandia-Ikobaltzeta I, Mustafa RA, Manja V, Brignardello-Petersen R, Neumann I, Falavigna M, Alhazzani W, Santesso N, Zhang Y, Meerpohl JJ, Morgan RL, Rochwerg B, Darzi A, Rojas MX, Carrasco-Labra A, Adi Y, AlRayees Z, Riva J, Bollig C, Moore A, Yepes-Nuñez JJ, Cuello C, Waziry R, Akl EA, GRADE Evidence to Decision (EtD) frameworks for adoption, adaptation, and de novo development of trustworthy recommendations: GRADE-ADOLOPMENT. J Clin Epidemiol. 2017 Jan;81:101-110.

21. Kristiansen A, Brandt L, Agoritsas T, Akl EA, Berge E, Bondi J, Dahm AE, Granan LP, Halvorsen S, Holme PA, Flem Jacobsen A, Jacobsen EM, Neumann I, Sandset PM, Sætre T, Tveit A, Vartdal T, Guyatt G, Vandvik PO. Adaptation of trustworthy guidelines developed using the GRADE methodology: a novel five-step process. Chest. 2014 Sep;146(3):727-734.

22. Kristiansen A, Brandt L, Agoritsas T, Akl EA, Berge E, Flem Jacobsen A, Granan LP, Halvorsen S, Guyatt G, Vandvik PO. Applying new strategies for the national adaptation, updating, and dissemination of trustworthy guidelines: results from the Norwegian adaptation of the Antithrombotic Therapy and the Prevention of Thrombosis, 9th Ed: American College of Chest Physicians Evidence-Based Clinical Practice Guidelines. Chest. 2014 Sep;146(3):735-761. 
23. Guyatt GH1, Oxman AD, Schünemann HJ, Tugwell P, Knottnerus A, GRADE guidelines: a new series of articles in the Journal of Clinical Epidemiology. J Clin Epidemiol. 2011 Apr;64(4):380-2.

24. MacLean, S., et al. Patient values and preferences in decision making for antithrombotic therapy: a systematic review: Antithrombotic Therapy and Prevention of Thrombosis, 9th ed: American College of Chest Physicians Evidence-Based Clinical Practice Guidelines. Chest, 2012. 141: e1S.

25. Bates, S.M., et al. Women's values and preferences and health state valuations for thromboprophylaxis during pregnancy: A cross-sectional interview study. Thromb Res, 2016. 140: 22.

26. https://thrombosiscanada.ca/clinicalguides/ Last accessed August 29, 2018. 
Figures and Tables

Fig. 1. Graphical depiction of evaluating the tradeoffs of VTE and bleeding.

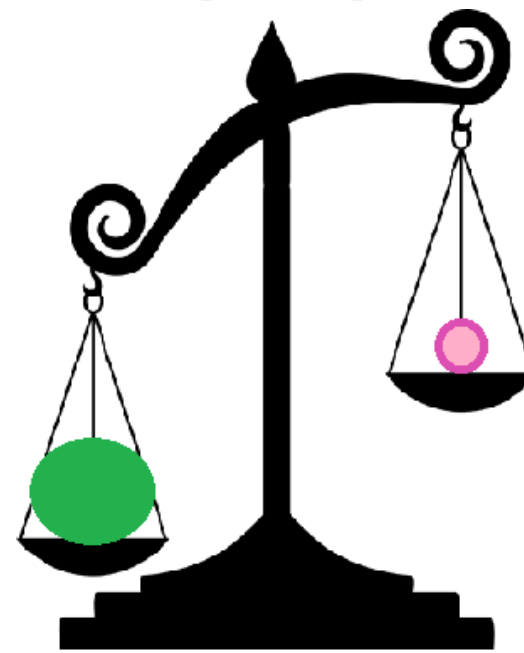

High Risk of VTE and Low risk of Bleeding favors Thromboprophylaxis

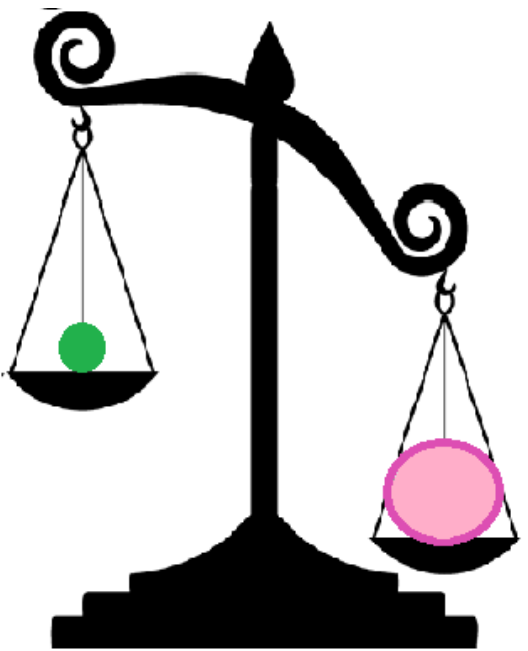

Low risk of VTE and High risk of Bleeding favors NO thromboprophylaxis

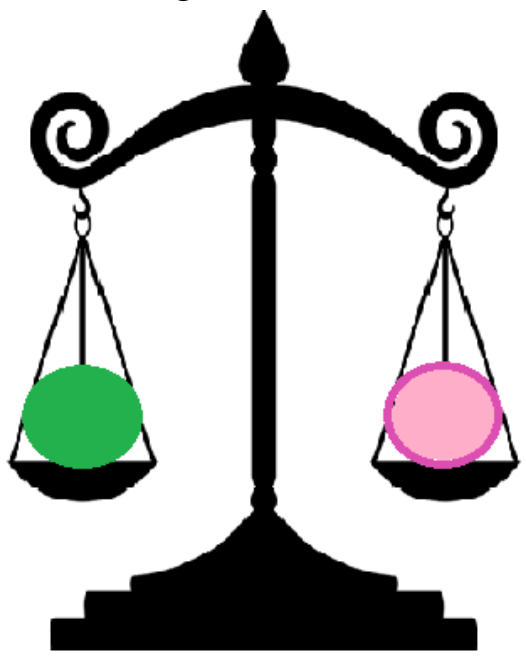

Similar risks of VTE and bleeding require discussion of patient values and preferences

Fig. 2. Cumulative incidence of post-operative VTE. Modified from Tikkinen KA, et al. Syst Rev 2014;3:150.

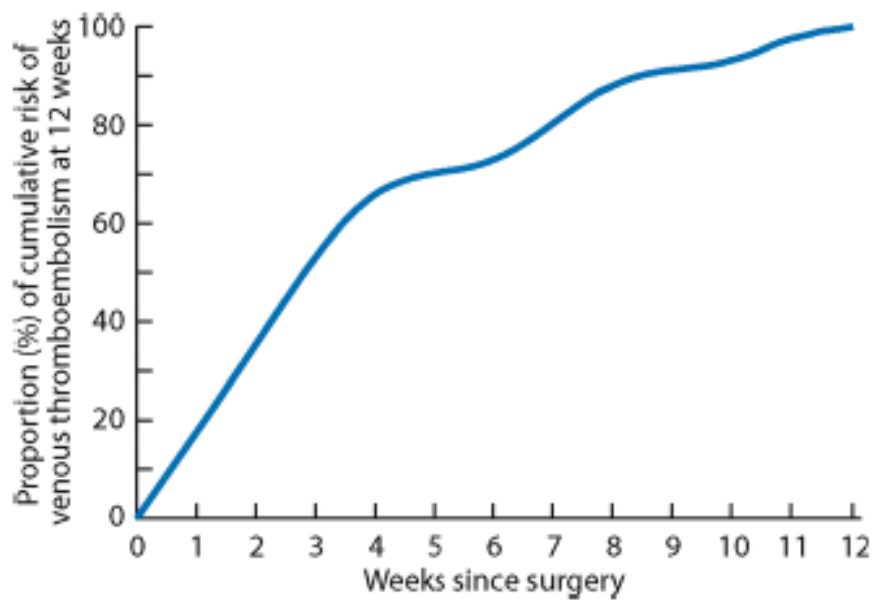


Fig.3. Cumulative incidence of VTE and bleeding in the first 4 weeks postoperatively. Modified from Tikkinen KA, et al. Syst Rev 2014;3:150.

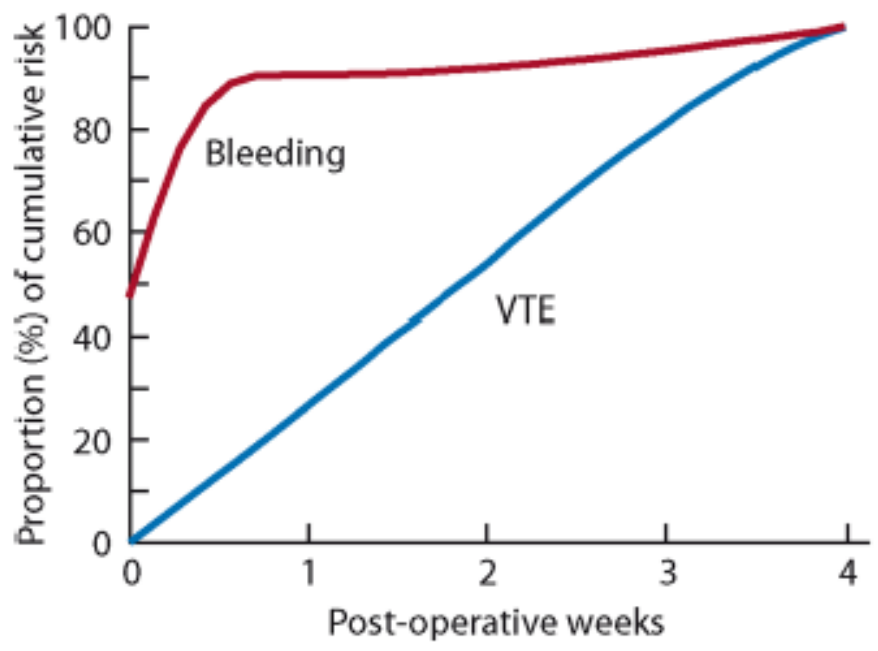

\begin{tabular}{|l|c|c|}
\hline Table 1. Patient level risk stratification for VTE \\
\hline Patient level factor & $\begin{array}{c}\text { Effect on VTE risk } \\
\text { (relative risk) }\end{array}$ & Risk stratification \\
\hline None & & Low risk \\
\hline Age $>75$ years & 2-fold & Moderate risk \\
\hline Body mass index $\geq 35$ & 2-fold & Moderate risk \\
\hline $\begin{array}{l}\text { VTE in a first-degree } \\
\text { relative (parents, full siblings, or } \\
\text { children) }\end{array}$ & 2-fold & Moderate risk \\
\hline Any 2 factors above & 4-fold & High risk \\
\hline Personal history of VTE & 4-fold & High risk \\
\hline
\end{tabular}


Guideline: Perioperative thromboprophylaxis \& anticoagulation management

\section{Supplementary Material}

\section{GRADE guideline methodology reference papers}

GRADE handbook:

http://gdt.guidelinedevelopment.org/central_prod/_design/client/handbook/handbook.html

Overview- Series in BMJ

1. GH, Oxman AD, Vist GE, Kunz R, Falck-Ytter Y, Alonso-Coello P, Schünemann HJ; GRADE Working Group. GRADE: an emerging consensus on rating quality of evidence and strength of recommendations. BMJ. 2008 Apr 26;336(7650):924-6

2. Guyatt GH, Oxman AD, Kunz R, Vist GE, Falck-Ytter Y, Schünemann HJ; GRADE Working Group. What is "quality of evidence" and why is it important to clinicians? BMJ. 2008 May 3;336(7651):995-8.

3. Guyatt GH, Oxman AD, Kunz R, Falck-Ytter Y, Vist GE, Liberati A, Schünemann HJ; GRADE Working Group. Going from evidence to recommendations. BMJ. 2008 May 10;336(7652):1049-51.

4. Schünemann HJ, Oxman AD, Brozek J, Glasziou P, Jaeschke R, Vist GE, Williams JW Jr, Kunz R, Craig J, Montori VM, Bossuyt P, Guyatt GH; GRADE Working Group. Grading quality of evidence and strength of recommendations for diagnostic tests and strategies. BMJ. 2008 May 17;336(7653):1106-10.

5. Guyatt GH, Oxman AD, Kunz R, Jaeschke R, Helfand M, Liberati A, Vist GE, Schünemann HJ; GRADE Working Group. Incorporating considerations of resources use into grading recommendations. BMJ. 2008 May 24;336(7654):1170-3.

6. Jaeschke R, Guyatt GH, Dellinger P, Schünemann H, Levy MM, Kunz R, Norris S, Bion J; GRADE Working Group. Use of GRADE grid to reach decisions on clinical practice guidelines when consensus is elusive. BMJ. $2008 \mathrm{Jul}$ 31;337:a744.

Evidence to decision framework- Series in BMJ

1. Alonso-Coello P, Schünemann HJ, Moberg J, Brignardello-Petersen R, Akl EA, Davoli M, Treweek S, Mustafa RA, Rada G, Rosenbaum S, Morelli A, Guyatt GH, Oxman AD; GRADE Working Group. GRADE Evidence to Decision (EtD) frameworks: a systematic and transparent approach to making well informed healthcare choices. 1: Introduction. BMJ. 2016 Jun 28;353:i2016.

2. Alonso-Coello P, Oxman AD, Moberg J, Brignardello-Petersen R, Akl EA, Davoli M, Treweek S, Mustafa RA, Vandvik PO, Meerpohl J, Guyatt GH, Schünemann HJ; GRADE Working Group. GRADE Evidence to Decision (EtD) frameworks: a systematic and transparent approach to making well informed healthcare choices. 2: Clinical practice guidelines. BMJ. 2016 Jun 30;353:i2089. 
Step-by-step how to apply GRADE- Series in J Clin Epi

1. Guyatt GH1, Oxman AD, Schünemann HJ, Tugwell P, Knottnerus A, GRADE guidelines: a new series of articles in the Journal of Clinical Epidemiology. J Clin Epidemiol. 2011 Apr;64(4):380-2.

2. Guyatt G, Oxman AD, Akl EA, Kunz R, Vist G, Brozek J, Norris S, Falck-Ytter Y, Glasziou P, DeBeer H, Jaeschke R, Rind D, Meerpohl J, Dahm P, Schünemann HJ. GRADE guidelines: 1. Introduction-GRADE evidence profiles and summary of findings tables. J Clin Epidemiol. 2011 Apr;64(4):383-94.

3. Langendam M, Carrasco-Labra A, Santesso N, Mustafa RA, Brignardello-Petersen R, Ventresca M, Heus P, Lasserson T, Moustgaard R, Brozek J, Schünemann HJ. Improving GRADE evidence tables part 2: a systematic survey of explanatory notes shows more guidance is needed. J Clin Epidemiol. 2016 Jun;74:19-27.

4. Santesso N, Carrasco-Labra A, Langendam M, Brignardello-Petersen R, Mustafa RA, Heus P, Lasserson T, Opiyo N, Kunnamo I, Sinclair D, Garner P, Treweek S, Tovey D, Akl EA, Tugwell P, Brozek JL, Guyatt G, Schünemann HJ. Improving GRADE evidence tables part 3: detailed guidance for explanatory footnotes supports creating and understanding GRADE certainty in the evidence judgments. J Clin Epidemiol. 2016 Jun;74:28-39.

5. Guyatt GH, Oxman AD, Vist G, Kunz R, Brozek J, Alonso-Coello P, Montori V, Akl EA, Djulbegovic B, Falck-Ytter Y, Norris SL, Williams JW Jr, Atkins D, Meerpohl J, Schünemann HJ. GRADE guidelines: 4. Rating the quality of evidence--study limitations (risk of bias). J Clin Epidemiol. 2011 Apr;64(4):407-15.

6. Guyatt GH, Oxman AD, Montori V, Vist G, Kunz R, Brozek J, Alonso-Coello P, Djulbegovic B, Atkins D, Falck-Ytter Y, Williams JW Jr, Meerpohl J, Norris SL, Akl EA, Schünemann HJ. GRADE guidelines: 5. Rating the quality of evidence--publication bias. J Clin Epidemiol. 2011 Dec;64(12):1277-82.

7. Guyatt GH, Oxman AD, Kunz R, Brozek J, Alonso-Coello P, Rind D, Devereaux PJ, Montori VM, Freyschuss B, Vist G, Jaeschke R, Williams JW Jr, Murad MH, Sinclair D, Falck-Ytter Y, Meerpohl J, Whittington C, Thorlund K, Andrews J, Schünemann HJ. GRADE guidelines 6. Rating the quality of evidence--imprecision. J Clin Epidemiol. 2011 Dec;64(12):1283-93.

8. Guyatt GH, Oxman AD, Kunz R, Woodcock J, Brozek J, Helfand M, Alonso-Coello P, Glasziou P, Jaeschke R, Akl EA, Norris S, Vist G, Dahm P, Shukla VK, Higgins J, FalckYtter Y, Schünemann HJGRADE guidelines: 7. Rating the quality of evidence-inconsistency. J Clin Epidemiol. 2011 Dec;64(12):1294-302.

9. Guyatt GH, Oxman AD, Kunz R, Woodcock J, Brozek J, Helfand M, Alonso-Coello P, Falck-Ytter Y, Jaeschke R, Vist G, Akl EA, Post PN, Norris S, Meerpohl J, Shukla VK, Nasser M, Schünemann HJ. GRADE guidelines: 8. Rating the quality of evidence-indirectness. J Clin Epidemiol. 2011 Dec;64(12):1303-10.

10. Guyatt GH, Oxman AD, Sultan S, Glasziou P, Akl EA, Alonso-Coello P, Atkins D, Kunz R, Brozek J, Montori V, Jaeschke R, Rind D, Dahm P, Meerpohl J, Vist G, Berliner E, Norris S, Falck-Ytter Y, Murad MH, Schünemann HJ. GRADE guidelines: 9. Rating up the quality of evidence. J Clin Epidemiol. 2011 Dec;64(12):1311-6. 
11. Brunetti M, Shemilt I, Pregno S, Vale L, Oxman AD, Lord J, Sisk J, Ruiz F, Hill S, Guyatt GH, Jaeschke R, Helfand M, Harbour R, Davoli M, Amato L, Liberati A, Schünemann HJ. GRADE guidelines: 10. Considering resource use and rating the quality of economic evidence. J Clin Epidemiol. 2013 Feb;66(2):140-50.

12. Guyatt G, Oxman AD, Sultan S, Brozek J, Glasziou P, Alonso-Coello P, Atkins D, Kunz R, Montori V, Jaeschke R, Rind D, Dahm P, Akl EA, Meerpohl J, Vist G, Berliner E, Norris S, Falck-Ytter Y, Schünemann HJ. GRADE guidelines: 11. Making an overall rating of confidence in effect estimates for a single outcome and for all outcomes. J Clin Epidemiol. 2013 Feb;66(2):151-7.

13. Guyatt GH, Oxman AD, Santesso N, Helfand M, Vist G, Kunz R, Brozek J, Norris S, Meerpohl J, Djulbegovic B, Alonso-Coello P, Post PN, Busse JW, Glasziou P, Christensen R, Schünemann HJ. GRADE guidelines: 12. Preparing summary of findings tables-binary outcomes. J Clin Epidemiol. 2013 Feb;66(2):158-72.

14. Guyatt GH, Thorlund K, Oxman AD, Walter SD, Patrick D, Furukawa TA, Johnston BC, Karanicolas P, Akl EA, Vist G, Kunz R, Brozek J, Kupper LL, Martin SL, Meerpohl JJ, Alonso-Coello P, Christensen R, Schunemann HJ. GRADE guidelines: 13. Preparing summary of findings tables and evidence profiles-continuous outcomes. J Clin Epidemiol. 2013 Feb;66(2):173-83.

15. Andrews J, Guyatt G, Oxman AD, Alderson P, Dahm P, Falck-Ytter Y, Nasser M, Meerpohl J, Post PN, Kunz R, Brozek J, Vist G, Rind D, Akl EA, Schünemann HJ. GRADE guidelines: 14 . Going from evidence to recommendations: the significance and presentation of recommendations. J Clin Epidemiol. 2013 Jul;66(7):719-25.

16. Andrews JC, Schünemann HJ, Oxman AD, Pottie K, Meerpohl JJ, Coello PA, Rind D, Montori VM, Brito JP, Norris S, Elbarbary M, Post P, Nasser M, Shukla V, Jaeschke R, Brozek J, Djulbegovic B, Guyatt G. GRADE guidelines: 15. Going from evidence to recommendation-determinants of a recommendation's direction and strength. J Clin Epidemiol. 2013 Jul;66(7):726-35.

17. Guyatt GH, Alonso-Coello P, Schünemann HJ, Djulbegovic B, Nothacker M, Lange S, Murad MH, Akl EA. Guideline panels should seldom make good practice statements: guidance from the GRADE Working Group. J Clin Epidemiol. 2016 Dec;80:3-7.

Good practice statements in GRADE

1. Guyatt GH, Alonso-Coello P, Schünemann HJ, Djulbegovic B, Nothacker M, Lange S, Murad MH, Akl EA. Guideline panels should seldom make good practice statements: guidance from the GRADE Working Group. J Clin Epidemiol. 2016 Dec;80:3-7.

Adapting international guidelines to a local context

1. Kristiansen A, Brandt L, Agoritsas T, Akl EA, Berge E, Bondi J, Dahm AE, Granan LP, Halvorsen S, Holme PA, Flem Jacobsen A, Jacobsen EM, Neumann I, Sandset PM, Sætre T, Tveit A, Vartdal T, Guyatt G, Vandvik PO. Adaptation of trustworthy guidelines developed using the GRADE methodology: a novel five-step process. Chest. 2014 Sep;146(3):727-734. 
2. Kristiansen A, Brandt L, Agoritsas T, Akl EA, Berge E, Flem Jacobsen A, Granan LP, Halvorsen S, Guyatt G, Vandvik PO. Applying new strategies for the national adaptation, updating, and dissemination of trustworthy guidelines: results from the Norwegian adaptation of the Antithrombotic Therapy and the Prevention of Thrombosis, 9th Ed: American College of Chest Physicians Evidence-Based Clinical Practice Guidelines. Chest. 2014 Sep;146(3):735-761.

3. Schünemann HJ, Wiercioch W, Brozek J, Etxeandia-Ikobaltzeta I, Mustafa RA, Manja V, Brignardello-Petersen R, Neumann I, Falavigna M, Alhazzani W, Santesso N, Zhang Y, Meerpohl JJ, Morgan RL, Rochwerg B, Darzi A, Rojas MX, Carrasco-Labra A, Adi Y, AlRayees Z, Riva J, Bollig C, Moore A, Yepes-Nuñez JJ, Cuello C, Waziry R, Akl EA, GRADE Evidence to Decision (EtD) frameworks for adoption, adaptation, and de novo development of trustworthy recommendations: GRADE-ADOLOPMENT. J Clin Epidemiol. 2017 Jan;81:101-110. 
Abbreviated summary of CUA recommendations for post-operative VTE prophylaxis

\begin{tabular}{|c|c|c|c|c|}
\hline \# & Surgery & $\begin{array}{r}\text { Phar } \\
\text { pr }\end{array}$ & $\begin{array}{l}\text { ological } \\
\text { ylaxis }\end{array}$ & $\begin{array}{l}\text { Mechanical } \\
\text { prophylaxis }\end{array}$ \\
\hline & & Risk stata & $\begin{array}{l}\text { Strength and } \\
\text { direction }\end{array}$ & $\begin{array}{l}\text { Strength and } \\
\text { direction }\end{array}$ \\
\hline 1 & $\begin{array}{l}\text { Radical cystectomy } \\
\text { (open or robotic) }\end{array}$ & All & Strong for & Weak for \\
\hline 2 & $\begin{array}{l}\text { Open prostatectomy } \\
\text { (without extended PLND) }\end{array}$ & $\begin{array}{c}\text { Low } \\
\text { Moderate or } \\
\text { high }\end{array}$ & $\begin{array}{l}\text { Weak for } \\
\text { Strong for }\end{array}$ & $\begin{array}{l}\text { Weak for } \\
\text { Weak for }\end{array}$ \\
\hline 3 & $\begin{array}{l}\text { Open prostatectomy } \\
\text { (extended PLND) }\end{array}$ & All & Strong for & Weak for \\
\hline 4 & $\begin{array}{l}\text { Robotic or laparoscopic } \\
\text { prostatectomy } \\
\text { (no PLND) }\end{array}$ & $\begin{array}{c}\text { Low } \\
\text { Moderate or } \\
\text { high }\end{array}$ & $\begin{array}{l}\text { Strong against } \\
\text { Weak against }\end{array}$ & $\begin{array}{l}\text { Weak against } \\
\text { Weak for }\end{array}$ \\
\hline 5 & $\begin{array}{l}\text { Robotic or laparoscopic } \\
\text { prostatectomy } \\
\text { (standard PLND) }\end{array}$ & $\begin{array}{c}\text { Low } \\
\text { Moderate } \\
\text { High }\end{array}$ & $\begin{array}{c}\text { Strong against } \\
\text { Weak against } \\
\text { Weak for } \\
\end{array}$ & $\begin{array}{l}\text { Weak for } \\
\text { Weak for } \\
\text { Weak for }\end{array}$ \\
\hline 6 & $\begin{array}{l}\text { Robotic or laparoscopic } \\
\text { prostatectomy } \\
\text { (extended PLND) }\end{array}$ & $\begin{array}{c}\text { Low } \\
\text { Moderate } \\
\text { High }\end{array}$ & $\begin{array}{c}\text { Weak against } \\
\text { Weak for } \\
\text { Strong for } \\
\end{array}$ & $\begin{array}{l}\text { Weak for } \\
\text { Weak for } \\
\text { Weak for }\end{array}$ \\
\hline 7 & $\begin{array}{l}\text { Open } \\
\text { - Radical nephrectomy } \\
\text { - Partial nephrectomy } \\
\text { - Nephroureterectomy }\end{array}$ & All & Weak for & Weak for \\
\hline 8 & $\begin{array}{l}\text { Laparoscopic } \\
\text { - Radical nephrectomy }\end{array}$ & $\begin{array}{c}\text { Low or } \\
\text { moderate } \\
\text { High } \\
\end{array}$ & $\begin{array}{c}\text { Weak against } \\
\text { Weak for }\end{array}$ & $\begin{array}{l}\text { Weak for } \\
\text { Weak for }\end{array}$ \\
\hline 9 & $\begin{array}{l}\text { Laparoscopic } \\
\text { - Partial nephrectomy }\end{array}$ & $\begin{array}{c}\text { Low or } \\
\text { moderate } \\
\text { High }\end{array}$ & $\begin{array}{c}\text { Weak against } \\
\text { Strong for }\end{array}$ & $\begin{array}{l}\text { Weak for } \\
\text { Weak for }\end{array}$ \\
\hline 10 & $\begin{array}{l}\text { Robotic } \\
\text { - Partial nephrectomy }\end{array}$ & $\begin{array}{l}\text { Low } \\
\text { Moderate } \\
\text { High }\end{array}$ & $\begin{array}{l}\text { Weak against } \\
\text { Weak for } \\
\text { Strong for }\end{array}$ & $\begin{array}{l}\text { Weak for } \\
\text { Weak for } \\
\text { Weak for }\end{array}$ \\
\hline 11 & $\begin{array}{l}\text { RPLND for testicular } \\
\text { germ cell cancer }\end{array}$ & All & Weak for & Weak for \\
\hline 12 & Ambulatory day surgery & All & Strong against & Weak against \\
\hline 13 & TURP & All & Weak against & Weak against \\
\hline 14 & $\begin{array}{l}\text { Nephrectomy for benign } \\
\text { disease }\end{array}$ & $\begin{array}{l}\text { Low or } \\
\text { moderate } \\
\text { High } \\
\end{array}$ & $\begin{array}{c}\text { Weak against } \\
\text { Weak for }\end{array}$ & $\begin{array}{c}\text { Weak against } \\
\text { Weak for }\end{array}$ \\
\hline 15 & $\begin{array}{l}\text { Continence and prolapse } \\
\text { surgery }\end{array}$ & All & Weak against & Weak against \\
\hline
\end{tabular}


Guideline: Perioperative thromboprophylaxis \& anticoagulation management

Abbreviated summary of CUA recommendations for peri-procedure management of anticoagulants and antiplatelet agents

\begin{tabular}{|c|c|c|c|c|}
\hline \# & Preoperative agent & $\begin{array}{l}\text { Stop } \\
\text { days } \\
\text { prior }\end{array}$ & $\begin{array}{l}\text { Start } \\
\text { days } \\
\text { post }\end{array}$ & Notes \\
\hline 16 & Antiplatelets & 7 days & 4 days & \multirow{5}{*}{$\begin{array}{l}\text { Excludes patients at very high risk } \\
\text { of thrombosis: } \\
\text { - DES within six months } \\
\text { - BMS within six weeks } \\
\text { - TIA or stroke within } 30 \text { days } \\
\text { - New VTE within } 1 \text { month } \\
\text { - Severe thrombophilia } \\
\text { - Cage-ball mechanical heart valves }\end{array}$} \\
\hline 17 & Direct oral anticoagulant & 3 days & 4 days & \\
\hline 17 & Warfarin & 5 days & 4 days & \\
\hline 17 & $\begin{array}{l}\text { LMWH } \\
\text { Twice daily formulation } \\
\text { Once daily formulation }\end{array}$ & $\begin{array}{l}12 \text { hours } \\
24 \text { hours }\end{array}$ & $\begin{array}{l}4 \text { days } \\
4 \text { days }\end{array}$ & \\
\hline 17 & Fondaparinux & 24 hours & 4 days & \\
\hline
\end{tabular}

Severe thrombophilia defined as anti-thrombin deficiency, protein C deficiency, antiphospholipid antibody, or other as identified by appropriate specialist. BMS: bare metal stent; DES: drug-eluting stent; TIA: transient ischemic attack. 